\title{
Espaço Europeu de Ensino Superior: marco regulatório que impacta na gestão das universidades brasileiras?
}

\author{
Egeslaine de Nez* \\ Antonio Bosco de Lima ${ }^{* *}$
}

\section{Resumo}

Este artigo tem como objetivo identificar se o Espaço Europeu do Ensino Superior (EEES), intitulado inicialmente como Processo/Tratado de Bolonha, é reconhecido como um movimento regulatório que influencia a gestão de instituições de Educação Superior no Brasil. O procedimento metodológico partiu de um estado da arte/estado de conhecimento dos documentos que compõem o Processo, assim como sobre o tema da regulação e contemplou a metodologia da análise de conteúdo. A abordagem analítica dos dados foi a pesquisa qualitativa. Nessa investigação, referenda-se que a reestruturação do sistema de ensino superior europeu, em curso desde o final da década de noventa, sob a égide do Processo de Bolonha, tem mobilizado diferentes e divergentes interpretações, colocando em pauta diversas categorias de análise. A relevância científica desta interlocução relaciona-se diretamente com o fato de apesar da existência desses estudos dedicados ao EEES, poucos são no âmbito dessa discussão, que tem como principal categoria a regulação, com foco descritivo na modalidade transnacional. Considera-se, finalmente, que há uma complexa relação de entrelaçamento entre a regulação transnacional e as políticas públicas educacionais contemporâneas que se articulam dinamicamente e servem como marcos regulatórios e/ou aportes teóricos para algumas ações das/nas instituições educacionais brasileiras.

Palavras-chave: Processo de Bolonha. Educação Superior. Gestão. Regulação. Impactos.

Recebido: 2/04/2015 - Aprovado: 13/08/2015

http://dx.doi.org/10.5335/rep.v22i2.5573

Doutora em Educação pela Universidade Federal do Rio Grande do Sul (UFRGS), mestre em Educação pela Universidade Estadual de Ponta Grossa (UEPG), Pedagoga e Especialista em Fundamentos da Educação pela Universidade Estadual do Oeste do Paraná (Unioeste). Atualmente é professora da Universidade do Estado de Mato Grosso (Unemat), Campus Universitário Vale do Teles Pires (Colider/MT). É líder do Grupo de Estudos sobre Universidade (GEU/ Unemat). E-mail: egeslaine@unemat.br

** Pós-doutor pela Unicamp na área de concentração História, Filosofia e Educação; doutor em Educação pela Pontifícia Universidade Católica de São Paulo; mestre em Educação pela Universidade Estadual de Campinas. Atualmente é Professor Associado da Universidade Federal de Uberlândia e coordena o Grupo de Pesquisa Estado, Democracia e Educação (GPEDE). E-mail: boscodelima@gmail.com 


\section{Considerações iniciais}

As políticas sociais não estão isentas da intervenção do Estado capitalista. Aliás, essas são produtos desse Estado. Servem aos interesses do capital, ou como sugere Vieira, "parte da estratégia da classe dominante, mais adequadamente da burguesia" (1992, p. 30). Isso que parece ser óbvio, no imaginário popular, não é assim tão simples. Afinal, as políticas públicas são moedas de troca, que parecem solucionar questões da miserabilidade (cultural, social, educacional, da segurança, dentre outras), mas apenas amenizam o teor de tais problemas.

Assim, na análise e na avaliação de políticas implementadas por um governo, fatores de diferentes natureza e determinação são importantes. A compreensão do conceito de políticas públicas é um fator relevante e pode ser caracterizado como o Estado em ação, isso significa dizer que se vincula à ideia de o Estado implantar um projeto de governo, por meio de programas e de ações voltadas a setores específicos da sociedade (HÖFLING, 2001).

É nessa conjuntura que este estudo se desenvolve, destacando uma política pública, com especificidade na Educação Superior, e um de seus principais marcos regulatórios: o Tratado de Bolonha. Para entendê-lo, torna-se necessário estabelecer algumas notas sobre a internacionalização do conhecimento. Neste trabalho, tal categoria está articulada ao mundo da produção, sob a custódia do capitalismo, que essencialmente volta-se para o mercado e para a circulação de mercadorias e, consequentemente, do conhecimento. Lógico, portanto, que a educação perde, nesse contexto, seu viés social e passa a ser tratada como uma mercadoria, que precisa, para ser viabilizada para garantir acúmulo e circular, o que significa ser comprada e vendida.

Este estudo parte do princípio que a reestruturação do sistema de ensino superior europeu, em curso desde o final da década de noventa, sob a égide do Processo de Bolonha, tem mobilizado inúmeras interpretações, colocando em pauta diversas categorias analíticas. A relevância científica desta pesquisa relaciona-se diretamente ao fato de apesar da existência desses estudos dedicados ao EEES, poucos são no âmbito dessa discussão que têm como principal categoria a regulação transnacional.

O grande questionamento dessa interlocução foi verificar se existem evidências de que esses marcos regulatórios poderiam ter impactado de alguma maneira na gestão das universidades brasileiras. Para isso, o percurso metodológico escolhido foi um estado da arte/estado de conhecimento (MOROSINI, 2006; FRANCO, 2011) dos documentos que compõem o Processo, assim como sobre o tema da regulação e contemplou a metodologia da análise de conteúdo (BARDIN, 1977; FRAN- 
CO, 2008). A abordagem analítica dos dados foi a pesquisa qualitativa (GIL, 1989; LAKATOS; MARCONI, 2010).

Nesse sentido, esse artigo está organizado em três eixos, além dessas considerações iniciais e das reflexões finais. O primeiro eixo apresenta o conceito de regulação, assim como suas instâncias: transnacional; nacional e microrregulação local. No segundo, traz-se a descrição sumária do Tratado/Processo de Bolonha, e, no terceiro eixo, o foco são as repercussões no plano nacional.

\section{Regulação: definição e tipologias}

Numa época marcada pelo impacto das tecnologias de informação e comunicação, deter e produzir conhecimento, bem como transformá-lo em inovações nas esferas econômica e social é um posicionamento estratégico de cada país (LIMA; CONTEL, 2011). Robertson (2009) destaca que esse movimento é o motor para o desenvolvimento de uma economia baseada no conhecimento. Reconhece-se, deste modo, a importância que a universidade tem, sobretudo na perspectiva de produção e transferência de conhecimentos.

Iniciativas nesse sentido, de caráter nacional, foram relevantes para a interiorização da Educação Superior, seja pela via do Decreto n⿳o 6.096/2007, que institui o Programa de Reestruturação e Expansão das Universidades Federais (Reuni) (BRASIL, 2007) - no âmbito público; seja pela aceleração do financiamento da educação via Lei no ${ }^{0}$ 10.260/2001 que trata do Fundo de Financiamento Estudantil (Fies) (BRASIL, 2009) ou de bolsas por meio da Lei $\mathrm{n}^{0}$ 11.096/2005 que constitui o Programa Universidade para Todos (ProUni) (BRASIL, 2008)- no âmbito privado. Além disso, a criação da Universidade Aberta do Brasil entre outros desdobramentos que ocorreram no sentido de massificar (quantificar) o número de egressos com formação superior atendendo a demandas exclusivas do capital.

Tais iniciativas, que ocorreram particularmente durante o governo Lula, em seus dois mandatos (2003-2010) visavam no campo da economia sustentar a tese de neodesenvolvimentismo econômico e social. Assim sendo, eleva-se o número de vagas na Educação Superior para formação de mão de obra para o capital, com base tecnológica.

Substancialmente, tem-se na Lei $\mathrm{n}^{-}$13.005/2014, que aprova o Plano Nacional de Educação (PNE), um teor de incremento na graduação e na Pós-graduação. No artigo 2 desse documento, que trata das diretrizes, destaca-se o inciso VII: promoção humanística, científica, cultural e tecnológica. Duas metas são fundamentais para potencializar tal objetivo: a Meta 12 - elevar a taxa bruta de matrícula na Educação Superior para 50\% e a taxa líquida para 33\% da população de 18 a 24 
anos, assegurada a qualidade da oferta e expansão para, pelo menos, $40 \%$ das novas matrículas; e, a Meta 14 - elevar gradualmente o número de matrículas na Pós-graduação Stricto Sensu, de modo a atingir a titulação anual de 60.000 mestres e 25.000 doutores (BRASIL, 2014).

Vale realçar que as Instituições de Educação Superior (IES) já vinham caminhando em direção a essas metas. As políticas, os programas e as práticas universitárias foram cada vez mais cooptadas e dimensionadas por interesses políticos e econômicos geoestratégicos, que sofrem injunções e suportam pressões ao longo de sua história. Barroso (2006) chama esse movimento de regulação e sinaliza que o conceito é polissêmico, descrevendo dois tipos de fenômenos diferentes e interdependentes que são: "os modos como são produzidas e aplicadas as regras que orientam a acção dos actores; os modos como esses mesmos actores se apropriam delas e as transformam" (2006, p. 12).

Cabrito define regulação como o "[...] modo como os portadores de autoridade coordenam, controlam e influenciam o sistema educativo e os seus actores, através de regras, normas, pressões e constrangimentos, condicionando a acção daqueles actores em função dos objectivos políticos que perseguem" (2011, p. 187). Assim, a regulação se concretiza nas ações dos ocupantes ocasionais que detém o poder, isso significa dizer, os indivíduos que têm a capacidade legal para implementar regras ou normas com êxito e que fazem valer suas decisões, materializadas em políticas públicas e/ou projetos e programas.

Segundo Dale (1998), a regulação pressupõe controle. Aqui, no caso específico da Educação Superior, as sanções legais que originam o domínio seria por meio da organização das atividades que o Estado impõe por meio do Ministério da Educação (MEC), da Coordenação de Aperfeiçoamento de Pessoal de Ensino Superior (Capes) e do Conselho Nacional de Desenvolvimento Científico e Tecnológico (CNPq). Assim, ao longo das décadas a regulação consegue um avanço na definição de padrões e regras, segundo os quais as IES brasileiras são forçadas a seguir e a respeitar.

Afinal, tratam-se de políticas que visam garantir o controle do Estado sobre a sociedade. Mas além do controle social, trabalha-se com o imaginário social, construindo-se uma ideia de acesso, de conquista e de evolução. Como referencia Faleiros, "A forma como as políticas sociais aparecem nos discursos, nos jornais, nas inaugurações faz parte do imaginário social da interação simbólica ou da ideologia dominante" (1991, p. 18).

Processualmente, como esclarece Barroso, acentua-se a relevância da regulação nos processos de recomposição do papel do Estado e na alteração dos seus modos de intervenção. Sendo resultado da busca de seu papel na "[...] definição, pilotagem e execução das políticas e da ação públicas, mas, por outro lado, ele passa a ser obrigado a partilhar esse papel com a intervenção crescente de outras 
entidades, e atores, que se reportam a referências, lugares e processos de decisão distintos" (2006, p. 11).

Para se compreender a natureza e a dimensão do processo regulatório na Educação Superior e as imbricadas interlocuções que se estabelecem entre os níveis global e local, considera-se útil recorrer às contribuições formuladas por Barroso em três instâncias: transnacional; nacional e microrregulação local. Esses três níveis se distinguem pelo lócus de sua atuação (hierarquia) e pela extensão e capacidade que têm de se impor ao conjunto das relações que se materializam entre os vários níveis de políticas públicas educacionais. Por regulação transnacional, Barroso compreende um:

[...] conjunto de normas, discursos e instrumentos (procedimentos, técnicas, materiais diversos, etc.) que são produzidos e circulam nos fóruns de decisão e consulta internacionais, no domínio da educação, e que são tomados, pelos políticos, funcionários ou especialistas nacionais, como "obrigação" ou "legitimação" para adoptarem ou proporem decisões ao nível do funcionamento do sistema educativo (2006, p. 44-45, grifos do autor).

Vale destacar que esse tipo de regulação tem sua origem em países centrais e faz parte do sistema de dependência em que se encontram os países periféricos, num quadro de constrangimentos estruturais de natureza política e econômica, que integram os chamados efeitos da globalização e que resultam na geopolítica do conhecimento e na internacionalização da Educação Superior (LIMA; CONTEL, 2011).

Barroso ressalta que esse tipo de regulação é resultado da existência de “[...] estruturas supranacionais - que mesmo não assumindo formalmente um poder de decisão em matéria educativa - controlam e coordenam, por meio das regras e dos sistemas de financiamento, a execução das políticas nesse domínio” (2006, p. 45).

Já com relação à discussão do conceito de regulação nacional, destaca-se que é o modo que as autoridades exercem a coordenação, o controle e a influência sobre o sistema educativo, orientando por meio de normas, o contexto da ação dos diferentes atores sociais e seus resultados. Barroso esclarece que:

Por um lado, e numa perspectiva diacrónica, assiste-se a um processo de sedimentação normativa que resulta da sobreposição de novas regras, orientações e reformas (produzidas numa volúpia de transformação permanente que raramente ultrapassa a superfície do sistema), às práticas e estruturas antigas que, na maior parte dos casos, acabam por subsistir ainda que "travestidas" de uma pretensa modernidade (2006, p. 53, grifo do autor).

Assim, se constitui nas formas institucionalizadas de intervenção do Estado e de sua administração na coordenação do sistema educativo. Para Nez (2013), o governo nacional ao definir marcos regulatórios para a educação se respalda nas diretrizes internacionais, mas deveriam recontextualizá-las para atender às suas 
demandas específicas e às particularidades de seu país que está imerso numa determinada conjuntura. $\mathrm{O}$ poder público acaba, deste modo, aperfeiçoando suas condições para o exercício da função regulatória.

A relação global/local obedece a uma essencialidade que está presente nas forças produtivas a serviço do capital. Então, a ação regulatória, que se segue ao marco reivindicatório irá conduzir o Estado fundando ou refundando uma "nova ordem burguesa, apoiado em um Estado diminuído em sua base social, mas burocraticamente eficaz para servir ao capital” (BORON, 1991, p. 81). Nas últimas décadas não se tem visto algo diferente disso, o Governo de Fernando Henrique Cardoso extremamente monetário e, posteriormente, o governo de Lula da Silva, praticando um ecletismo entre o social e o monetarismo, que vem se perpetuando no atual mandato da Presidenta Dilma Rousseff.

A compreensão da disposição regulatória de conselhos específicos ou de espaços locais diversos é importante para se perceber algumas das tensões existentes na Educação Superior. Surge, então, a terceira e última instância é a microrregulação local, sendo considerada "o processo de coordenação da acção dos actores no terreno que resulta do confronto, interacção, negociação ou compromisso de diferentes interesses, lógicas, racionalidades e estratégias [...]" (BARROSO, 2006, p. 56-57). Dessa forma, está relacionada ao complexo jogo de estratégias, negociações e ações de vários atores na qual as normas e injunções da regulação nacional ou transnacional são (re) ajustadas localmente.

Enfim, pode-se enfatizar que o termo regulação está associado à intervenção do Estado na definição dos processos de gestão das atividades universitárias. É, sendo assim, uma forma de controle, organização das normas e função essencial para a manutenção do equilíbrio ou transformação de qualquer sistema. É exatamente nesse ínterim, que as reflexões deste artigo se fundamentam e se articulam com foco analítico para a regulação transnacional, como é o caso do Processo de Bolonha.

Estado, globalização, local, espaço, obedecem as leis maiores de mercado, as quais tendem a regular e não serem reguladas no sistema capitalista. Portanto, a regulação transnacional visa o intercâmbio, o reconhecimento, a relação sem entraves para a circulação das várias mercadorias, dentre as quais, a que se tratou: a Educação Superior.

Novamente, recorrendo a Boron (1991), o "desenvolvimento capitalista requereu o desmantelamento sistemático das instituições, práticas e valores tradicionalmente associados com a democracia burguesa" (p. 87). Visa, portanto, o desmantelamento do nacional, do local, das fronteiras, e o primado do capital internacional, globalizado, mundializado, de valores centrais sobre os "periféricos", de tecnologias 
primeiro mundista sobre as "pseudo tecnologias do terceiro mundo", sinalizando o Tratado de Bolonha para o seu incremento nas várias nacionalidades.

\section{Descrevendo o EEES}

O Processo de Bolonha foi intitulado oficialmente como EEES e ocupa um papel de destaque na última década nas discussões da Educação Superior, não apenas na Europa, mas, também, no restante do mundo. Inicialmente, foi compreendido como um Tratado, contudo, ao longo dos anos, se transformou num lócus, como o próprio título expõe, o espaço privilegiado de elucubrações teóricas-políticas do ensino europeu.

"Podem-se empreender distintas análises sobre ele, mas é cada vez mais difícil ignorar sua força e impacto. A dimensão que ocupa hoje a Declaração de Bolonha está visceralmente relacionada ao contexto no qual esse acordo ganha existência" (WIELEWICKI e OLIVEIRA, 2010, p. 222). É, destarte, uma das transformações mais importante na história das universidades européias desde o início do século XIX que se articula diretamente a internacionalização do conhecimento e da Educação Superior.

Segundo Morosini (2006) a internacionalização é um termo utilizado há bastante tempo e conceituado de inúmeras maneiras. Há diversos estudos sobre a internacionalização, alguns tratam da relação entre a universidade e o conhecimento, há outras investigações específicas que a conceituam e a correlacionam com a globalização, com a transnacionalização, entre outros processos que integram essa conjuntura.

Para Bastos (2008) o Processo de Bolonha foi uma renovação relevante para inserir a Europa novamente num contexto desenvolvimentista no que diz respeito à qualificação de seus profissionais e à competitividade. Todavia, se reporta e se relaciona diretamente com algumas tendências, tais como: a globalização da economia acompanhada de um fluxo transnacional de capitais e o estabelecimento de acordos comerciais, resultando na internacionalização do comércio, além da reestruturação do mercado de trabalho.

O EEES se constituiu inicialmente a partir da Carta Magna (1988) que considerava que o futuro da humanidade dependia em larga medida do desenvolvimento cultural, científico e técnico das universidades. Dez anos depois, a Declaração de Sorbonne (1998) lançou a proposta de harmonizar a arquitetura do Sistema Europeu do Ensino Superior e, em, 1999 foi sistematizado o documento oficial designado de Declaração Conjunta que marcou a formalização da ideia da transformação do ensino superior na Europa (FRANÇA, 2013). 
A partir de então, foram publicados seis comunicados (Praga/2001, Ber$\mathrm{lim} / 2003$, Bergen/2005, Londres/2007, Leuven/Louvain-la-Neuve/2009 e Bucareste/2012) e uma nova declaração (Budapeste-Viena/2010). Todos esses documentos desvelam os avanços da constituição do EEES e a análise do Processo de Bolonha 2020. Além disso, enfatizam os ciclos acadêmicos, a concentração e transferência de créditos curriculares, a mobilidade dos envolvidos e a unificação e colaboração dos países-membros na expansão do ensino superior (Disponível em: <http://europa.eu/legislation_summaries/education_training_youth/lifelong_learning/c11088_ pt.htm>. Acesso em: 3 jan. 2013).

O quadro cronológico de todo o Processo que possibilita uma melhor compreensão é o que segue:

Tabela 1: Cronologia do Processo de Bolonha

\begin{tabular}{|c|c|c|}
\hline Data & Documento & Descrição analítica \\
\hline 1988 & Carta Magna & $\begin{array}{l}\text { Documento das universidades européias no qual arima-se que o } \\
\text { futuro da humanidade, neste fim de milênio, depende em larga me- } \\
\text { dida do desenvolvimento cultural, científico e técnico das universi- } \\
\text { dades. }\end{array}$ \\
\hline 1998 & Declaração de Sorbonne & $\begin{array}{l}\text { Pretendeu harmonizar a arquitetura do Sistema Europeu do Ensino } \\
\text { Superior. }\end{array}$ \\
\hline 1999 & Declaração de Bolonha & $\begin{array}{l}\text { Documento oficial chamado de Declaração Conjunta, marca a for- } \\
\text { malização da ideia da transformação do ensino superior na Europa. }\end{array}$ \\
\hline 2001 & Comunicado de Praga & $\begin{array}{l}\text { Intitulado Rumo ao Espaço Europeu do Ensino Superior, reafirman- } \\
\text { do o compromisso do estabelecimento da Declaração de Bolonha } \\
\text { até } 2010 \text {. }\end{array}$ \\
\hline 2003 & Comunicado de Berlin & $\begin{array}{l}\text { Apresentou como foco a realização do Espaço Europeu do Ensino } \\
\text { Superior. }\end{array}$ \\
\hline 2005 & Comunicado de Bergen & $\begin{array}{l}\text { Destaque para o Espaço Europeu do Ensino Superior e resposta } \\
\text { aos desafios de um mundo globalizado. }\end{array}$ \\
\hline 2007 & Comunicado de Londres & $\begin{array}{l}\text { Espaço Europeu do Ensino Superior e a resposta aos desafios de } \\
\text { um mundo globalizado eram a sua preocupação. }\end{array}$ \\
\hline 2009 & $\begin{array}{l}\text { Comunicado de Leuven/ } \\
\text { Louvain-la-Neuve }\end{array}$ & $\begin{array}{l}\text { Apresentou a análise do Processo de Bolonha } 2020 \text { e o Espaço } \\
\text { Superior na nova década. }\end{array}$ \\
\hline 2010 & $\begin{array}{l}\text { Declaração de Budapeste- } \\
\text {-Viena }\end{array}$ & $\begin{array}{l}\text { Reunião comemorativa do EEES, não especificamente ministerial } \\
\text { como as outras. }\end{array}$ \\
\hline 2012 & Comunicado de Bucareste & Consolidação do Espaço Europeu do Ensino Superior. \\
\hline
\end{tabular}

Fonte: Adaptado de Nez (2012).

O grande objetivo do Processo de Bolonha era a convergência dos sistemas baseados em três ciclos (licenciatura, mestrado e doutorado), também buscava introduzir um sistema de graus acadêmicos, promovendo a mobilidade dos estudantes, dos professores e dos pesquisadores. Ao longo do Processo foram acrescentados ou- 
tros elementos, tais como: aprendizagem ao longo da vida, competitividade econômica, atratividade aos estudantes, professores e pesquisadores, acreditação, cooperação, avaliação, qualidade, entre outros (Disponível em: <http://europa.eu/legislation_summaries/education_training_youth/lifelong_learning/c11088_pt.htm>).

Trinta países europeus assinaram a carta de intenções da declaração e hoje mais de quarenta e sete países participam do EEES, o que de alguma forma demonstra a capacidade de articulação, e de proposição de uma política pública transnacional. Hortale e Mora (2004) destacam que a Declaração de Bolonha não se caracteriza como um mandato da União Europeia (UE) que obriga os países-membros ao seu cumprimento; é, pois, um acordo que tem validade se os governos o implementarem em seus países. Poder-se-ia dizer que é "[...] um processo de todas e de cada uma das nações europeias em que a UE atua como dinamizadora" (p. 946). Com isso, esclarece-se o papel decisivo que a comunidade acadêmica teve para tornar o EEES uma realidade.

Morosini (2006) enfatiza que a declaração partia do pressuposto que a "Europa do Conhecimento" era um fator imprescindível ao crescimento social e humano, elemento indispensável à consolidação e ao enriquecimento da UE, capaz de oferecer aos seus cidadãos as aptidões necessárias para enfrentar os desafios do novo milênio.

Os seus efeitos foram imediatos, aparecendo como destaque nas discussões da Educação Superior, apesar da constatação de que sua aplicação e seu avanço seria lento, progressivo e demorado. Nez, Nez e Biavatti (2014) enfatizam que o Processo de Bolonha visava trazer a Europa de volta ao cenário de importância para a Educação Superior, com posição de destaque perdida durante o tempo em que ficou estagnada e não acompanhou o processo de desenvolvimento global.

Alinhado a essas reflexões, Siebiger (2013) considera que a concepção do EEES apresenta uma política que busca conciliar cooperação, liberdade acadêmica, autonomia institucional, princípios democráticos, aliada às ideias de igualdade de oportunidades, atratividade, competitividade e atendimento a demandas do mercado do trabalho.

Em sendo dessa forma, conclui-se que o EEES gerou um período intenso de atividades políticas e universitárias na Europa. Porém, é notório que esse movimento não surgiu no âmago das universidades, e sim sob o comando dos dirigentes políticos. Segundo Nez (2011), tem-se a nítida impressão de que o governo estava mais consciente dos problemas da Educação Superior, do que necessariamente a comunidade acadêmica, e essa intencionalidade deve ser considerada na análise do EEES. No entanto, não se pode ignorar que a toda política está subjacente uma intencionalidade teórica e que o pano de fundo em que se constitui está regado pelos interesses globais internacionais. 


\section{Repercussões e análises preliminares do caso brasileiro}

Como apresentado inicialmente o teor ideológico do Tratado de Bolonha está na possiblidade de, enquanto mercadoria, ter um "luxo internacionalizado". Portanto, sistemas de credenciamento, de transferência de créditos, de reconhecimento de diplomas, mobilidade estudantil estão presentes nas políticas sejam curriculares, sejam de mobilidade, sejam de articulações acadêmicas.

No Brasil, tem-se o Decreto no 7.642/2011 que cria o Programa Ciência sem Fronteiras (CIÊNCIA, 2013) que promove expansão e internacionalização da ciência, da tecnologia, da inovação e da competitividade brasileira, por meio do intercâmbio e da mobilidade internacional, além da especificidade da formação do pesquisador. Essa ideia implica o empresariamento da atividade científica. Prevê-se

[...] até 101 mil bolsas em quatro anos para promover intercâmbio, de forma que alunos de graduação e pós-graduação façam estágio no exterior com a finalidade de manter contato com sistemas educacionais competitivos em relação à tecnologia e inovação. Além disso, busca atrair pesquisadores do exterior que queiram se fixar no Brasil ou estabelecer parcerias com os pesquisadores brasileiros nas áreas prioritárias definidas no Programa, bem como criar oportunidade para que pesquisadores de empresas recebam treinamento especializado no exterior (CIÊNCIA, 2013, p. 1).

Santos (2014), em estudo sobre esse Programa, expõe que é uma iniciativa que visa melhorias no meio acadêmico, todavia, há uma questão social e financeira envolvida. Diversos acadêmicos e profissionais de algumas áreas não são contempladas e estão suprimidos dessa ação governamental. O que se evidencia é que o Ciência sem Fronteiras contempla devido a motivadores políticos, sociais e econômicos oferece certa preferência a algumas áreas, tais como: Engenharias, Tecnologias e Saúde.

Desse modo, parece inegável considerar que o Tratado/Processo de Bolonha é uma forma de igualar a Educação Superior nos países-membros, com o foco principal na adequação de seus sistemas curriculares, visando mobilidade que favorece $o$ desenvolvimento da pesquisa e seu financiamento. Essas ações pretendem manter pesquisadores no espaço da União Europeia consolidando-a como centro de excelência da educação, fazendo com que se torne precursora de uma nova tendência em educação mundial. Aplica-se, assim, a regulação transnacional.

Porém, para além da mobilidade da acreditação têm-se mudanças substanciais que ocorreram com os Projetos Políticos Pedagógicos (PPP) dos cursos de graduação no Brasil, que foram iniciados com a chamada no Edital no $4 / 97$ que convoca as IES a apresentar propostas para as novas diretrizes curriculares dos cursos superiores (BRASIL, 2014a). Esse conclama as IES a realizarem suas mudanças curriculares, 
focando, principalmente a formação "bacharelesca". A partir desse ato regulatório nacional relacionado ao EEES, os cursos foram se especializando e reestruturando.

É imprescindível comentar que o item 1 deste edital reforça que as diretrizes objetivam:

[...] servir de referência para as IES na organização de seus programas de formação, permitindo uma flexibilidade na construção dos currículos plenos e privilegiando a indicação de áreas do conhecimento a serem consideradas, ao invés de estabelecer disciplinas e cargas horárias definidas.

As Diretrizes Curriculares devem contemplar ainda a denominação de diferentes formações e habilitações para cada área do conhecimento, explicitando os objetivos e demandas existentes na sociedade (BRASIL, 2014a).

Mesmo que não sejam encontradas referências explícitas ao Tratado de Bolonha nas Diretrizes e nos PPP dos cursos de graduação, identifica-se em termos conceituais e essenciais que estão sinalizados nos termos: flexibilidade, habilidades, competências, dentre outros que demarcam e regulam os parâmetros para a constituição dos cursos.

Outro programa vinculado a tais orientações é o Projeto Tuning América Latina, que foi articulado em várias IES brasileiras, buscando uma afinação da Educação Superior ao modelo europeu. No Brasil, algumas universidades federais já possuem esse mesmo formato de arquitetura acadêmica, o Estado de Minas Gerais foi um dos precursores nesse tipo de formação, que na legislação brasileira intitulam-se Bacharelados Interdisciplinares (BI) (NEZ, 2011). Na Universidade Federal de Uberlândia, por exemplo, pode-se encontrar no PPP do Curso de Engenharia referência a tal programa, principalmente no que diz respeito ao perfil do egresso e a creditação.

Para Rasco (2008): “[...] surgen ideas como la convergencia en grados y postgrados, la facilitación de la movilidad de estudiantes y docentes, la adopción del European Credit Transfer System (ECTS)", além disso, "los procesos para asegurar la calidad de las universidades, así como el énfasis en el aprendizaje a lo largo de la vida y en la extensión y promoción mundial del sistema europeo de universidades" (p. 16). Expressões máximas do Processo de Bolonha que se mostram aparentes também nas universidades brasileiras.

Outro estudo importante foi realizado por Nez, Nez e Biavatti (2014) e se baseou na reflexão de quais impactos que a adoção do Processo de Bolonha pode causar nos Programas de Pós-graduação na área das Ciências Contábeis e que reflexos poderiam existir na estrutura da formação docente e discente. Os resultados encontrados apresentam que é inegável que o EEES é uma forma de igualar a Educação Superior nos países-membros, com o foco principal na adequação de seus sistemas curriculares. 
Especificamente com relação aos modelos acadêmicos que de alguma maneira se alinhavam a gestão das IES, Nez, Nez e Biavatti (2014) comentam ainda que se a implementação das propostas for viabilizada totalmente no Brasil toda a arquitetura de ensino será alterada, desde a estrutura, passando pelos docentes e discentes, instaurando tensões e avanços. Como é perceptível, vários são as repercussões provocadas pelo EEES na gestão das universidades brasileiras, este estudo objetivou oferecer alguns elementos analíticos para o desvelamento da compreensão do marco regulatório transnacional provocado pelo Processo.

\section{Algumas considerações}

O foco central desse trabalho foi o de realizar uma explanação sobre o EEES e a sua influência no Brasil. Foram discutidas brevemente as concepções do mundo do capital, por meio de seus instrumentos de internacionalização, globalização, mundialização e como repercute nas experiências nacionais. Isso foi identificado na política educacional implementada nas últimas décadas (final do século XX e início do século XXI), desde o Edital no 4/97, passando pelo PNE de 2014, pelas mudanças de diretrizes curriculares, pelas adaptações de financiamento referenciadas, além de discussões pertinentes em vasta literatura da área (LIMA, 2014) que tem privilegiado o primado do privado.

A partir da análise de conteúdo dos documentos que compõem o EEES, é possível enfatizar que, a cada encontro, os comunicados têm maior refinamento de idéias e aprofundamento teórico. Ao longo do processo foi perceptível a ênfase no contexto mundial com base da internacionalização da Educação Superior e na sociedade do conhecimento, além da sistematização de um possível alinhamento mundial, compondo a regulação transnacional.

Isso se mostra aparente nas atividades realizadas pelo Processo que estão articuladas e inscrevem-se nos objetivos do programa Educação e Formação 2020 e Europa 2020, como uma política pública para a Educação Superior nesses países. Assim, a adoção de um sistema de dois ciclos, em particular, já alterou a arquitetura do sistema de ensino superior europeu de uma forma inédita e profunda e de forma definitiva demarca ações noutros países, caso do Brasil analisado nesse estudo.

É imprescindível aqui nesse momento conclusivo das reflexões sobre o EEES compreender que pode ser aclamado como uma regulação do tipo transnacional. Ratifica-se que é categorizado como uma regulação burocrática e administrativa, sujeita a uma rede complexa de normativas (diretrizes e metas propostas nos comunicados e nas declarações) que reforçam a intervenção direta do Estado (através 
dos Ministros seus representantes legais), que teve como função reconfigurar a oferta da Educação Superior europeia.

Cada contexto de ação (transnacional, nacional, local) é fonte e palco da regulação institucional e situacional. Isso porque a ação política das sociedades ocorre sempre condicionada por regras e recursos protagonizados e disponibilizados por atores no quadro de relações sociais com certo grau de institucionalização, na especificidade desta investigação, na gestão das IES brasileiras.

Salienta-se, finalmente, que coexistem algumas diferenças nas três formas regulatórias exercidas nos diversos espaços (global, nacional e local), mas todas servem, igualmente, como uma possibilidade de organização das ações, políticas e práticas da Educação Superior brasileira.

Os desdobramentos do EEES ainda estão sendo desvelados, sendo que não se pode analisá-lo de modo finalístico, é necessário nesse ínterim certo tempo para reflexão dos impactos na gestão das universidades. Porém, o que já é perceptível é que sua presença "discreta e marcante" na reorganização curricular de vários cursos das instituições brasileiras. Isso é extremamente significativo, pois altera a formação recebida no espaço acadêmico.

\section{European higher education area (ehea): regulatory framework that impacts the management of brazilian universities?}

\section{Abstract}

This article aims to identify the European Higher Education Area (EHEA), entitled initially as Process/ Bologna Treaty, is recognized as a regulatory movement that influences the management of higher education institutions in Brazil. The methodological procedure begins with a state of the art/state of knowledge of the documents that make up the process as well as on the subject of regulation and included the methodology of content analysis. The analytical approach of the data was qualitative research. In this investigation, referenda that the restructuring of the European higher education system, in place since the end of the nineties, under the aegis of this process, has mobilized different and differing interpretations, putting on the agenda several categories of analysis. The scientific importance of this dialogue is directly related to the fact that despite the existence of these studies dedicated to the EHEA, few within this discussion whose main category to regulation, with descriptive focus on transnational mode. It is considered finally, there is a complex relationship of entanglement between the transnational regulation and contemporary educational policies that dynamically articulate and serve as regulatory frameworks and/or theoretical contributions to some actions of/in Brazilian educational institutions.

Keywords: Bologna Process. Higher Education. Management. Regulation. Impacts. 


\section{Referências}

BARDIN, L. Análise de conteúdo. 4. ed. Lisboa: Edições 70, 1977.

BARROSO, J. (Org.). A regulação das políticas públicas de educação: espaços, dinâmicas e actores. Lisboa: Educa/Unidade de I\&D de Ciências da Educação, 2006.

BASTOS, C. C. B. C. O Processo de Bolonha no espaço europeu e a reforma universitária brasileira. Educação temática digital. Brasília, jan. 2008.

BORON, A. A. Estado, capitalismo e democracia na América Latina. São Paulo: Paz e Terra, 1991.

BRASIL. Diretrizes gerais do decreto n. 6096 REUNI: Reestruturação e expansão das universidades federais. 2007. Disponível em: <http://portal.mec.gov.br/sesu/arquivos/pdf/diretrizesreuni. pdf>. Acesso em: 19 fev. 2012.

Edital n. 4/97. Disponível em: <http://portal.mec.gov.br/sesu/arquivos/pdf/e04.pdf>. Acesso em: 14 jul. 2014a.

. Fundo de financiamento estudantil (Fies). Disponível em: <http://sisfiesportal.mec.gov. br/leis.html>. Acesso em: 15 fev. 2009.

. Lei n. 13.005 / 2014 que aprova o plano nacional de educação (PNE). Disponível em: http:// www.planalto.gov.br/ccivil_03/_Ato2011-2014/2014/Lei/L13005.htm. Acesso em: 15 jul. 2014b.

Programa universidade para todos (ProUni). Disponível em: <http://prouni-inscricao. mec.gov.br/prouni/>. Acesso em: 25 out. 2008.

CABRITO, B. Políticas de regulação e mudanças recentes no ensino superior em Portugal. In: CABRAL NETO, A.; NASCIMENTO, I. V.; CHAVES, Vera Jacob (Org.). Política de expansão da educação superior no Brasil: democratização às avessas. São Paulo: Xamã, 2011.

CIÊNCIA sem fronteiras. Decreto n. 7.642, de 13 de dezembro de 2011. Disponível em: <http:// www.planalto.gov.br/ccivil_03/_Ato2011-2014/2011/Decreto/D7642.htm>. Acesso em: 28 set. 2013.

DALE, R. The State and the governance of education: an analysis of the restructuring of the State-Education relationship. In: HALSEY, A. H. et al. (Ed.). Education, culture, economy, and society. Oxford: Oxford University Press, 1998.

FALEIROS, V. P. O que é política social. São Paulo: Brasiliense, 1991.

FRANCO, M. E. D. P. Construção de conhecimento acerca da qualidade na gestão da educação superior. MOROSINI, M. C. (Org.). Qualidade na educação superior: reflexões e práticas investigativas. v. 3. Porto Alegre: Edipucrs, 2011.

FRANCO, M. L. P. B. Análise do conteúdo. Brasília: Liber Livro, 2008.

FRANÇA. Declaração de Sorbonne. Sorbonne, 1998. Disponível em: <http://www.uc.pt/ge3s/pasta_docs/outros_docs/decl_sorbonne>. Acesso em: 4 jan. 2013.

GIL, A. C. Métodos e técnicas de pesquisa social. 2. ed. São Paulo: Atlas, 1989.

HOFLING, E. M. Estado e políticas (públicas) sociais. Caderno Cedes. Campinas, v. 21, n. 55, nov. 2001. p. 30-41. 
HORTALE, V. A.; MORA, J. G. Tendências das reformas da educação superior na Europa no contexto do Processo de Bolonha. Educação e sociedade. Campinas, v. 25, n. 88, out. 2004. p. 937-960.

PROCESSO DE BOLONHA: estabelecimento do Espaço Europeu do Ensino Superior. Disponível em: <http://europa.eu/legislation_summaries/education_training_youth/lifelong_learning/ c11088_pt.htm>. Acesso em: 3 jan. 2013.

LAKATOS, E. M.; MARCONI, M. A. Metodologia científica. 5. ed. São Paulo: Atlas, 2010.

LIMA, A. B. (Org.). Qualidade da educação superior: o Programa REUNI. São Paulo: Paco Editorial, 2014.

LIMA, M. C.; CONTEL, F. B. Internacionalização da educação superior: nações ativas, nações passivas e a geopolítica do conhecimento. São Paulo: Alameda, 2011.

MOROSINI, M. Estado do conhecimento sobre internacionalização da educação superior - conceitos e práticas. Educar. Curitiba, n. 28. Universidade Federal do Paraná (UFPR). 2006.

NEZ, E. Estado da arte dos planos nacionais da pós-graduação brasileira (1975 a 2011). Seminário de Educação SEMIEDU. Cuiabá: UFMT, 2013.

Processo de Bolonha: instrumento de captação dos jovens pesquisadores para a construção de um espaço hegemômico de investigação. V Colóquio internacional educação e contemporaneidade. São Cristóvão: UFES, 2011.

Espaço europeu de ensino superior (EEES): política pública para a construção de um pensamento hegemômico. Seminário ANPAE Região Sul. Pelotas: UFPel, 2012.

.; NEZ, E. BIAVATTI, V. T. A internacionalização da educação superior e os impactos do Processo de Bolonha nos programas de pós-graduação brasileiros. Educação, cultura e sociedade (ECS). Sinop, v. 4, n. 1, ed. esp. jun. 2014. p. 34-48.

RASCO, F. A. La voluntad de distracción: las competencias en la universidad. 2008. Disponível em: <http://firgoa.usc.es/drupal/files/universidad.pdf>. Acesso em: 12 mar. 2011.

ROBERTSON, S. L. O processo de Bolonha da Europa torna-se global: modelo, mercado, mobilidade, força intelectual ou estratégia para construção do Estado? Revista Brasileira de Educação. V. 14, n. 42. set./dez. 2009. p. 407-422.

SANTOS, E. Internacionalização da educação superior através do programa ciência sem fronteiras. Trabalho de conclusão de curso de licenciatura em computação da Universidade do Estado de Mato Grosso (Unemat). Colider, 2014.

SIEBIGER, R. H. O processo de Bolonha e a universidade brasileira: aproximações e distanciamentos a partir da análise de documentos referenciais. Dissertação de mestrado, Programa de Pós-graduação em Educação da Universidade Federal da Grande Dourados (UFGD). Dourados, 2013.

VIEIRA, E. Democracia e política social. São Paulo: Cortez; Campinas: Autores Associados, 1992.

WIELEWICKI, H. G.; OLIVEIRA, M. R. Internacionalização da educação superior: processo de Bolonha. Ensaio: avaliação política pública educacional, Rio de Janeiro, v. 18, n. 67, p. 215-234, abr./jun. 2010. 